\title{
Thiophene Linked Porphyrin Derivatives for Dye Sensitized Solar Cell
}

\author{
Villari A. Nuay, Dong Hee Kim, Sang Hee Lee, ${ }^{\star}$ and Jaejung $\mathrm{Ko}_{0}{ }^{* *}$ \\ Deparment of Chemistry, Kunsan National Lniversity, Kunsan 573-701, Korea. E-mail leeshyakunsan.ac.kr \\ ${ }^{\dagger}$ Department of Material Chemistry, Korea Universitw, Jochin'on 339-700. Korea. * E-mail: jkoiákorea ack \\ Received September 3, 2009, Accepted October 8, 2009
}

Key Words: Dye sensitized solar cell, Thiophene. Porphyrin. Aggregation

Porphyrins have long been studied as promising components of molecular electronic and photonic devices. 'Since the earliest reports of the efficient charge injection into nanocrystalline $\mathrm{TiO}_{2}$ by covalently bound zinc tetrakis(4-carboxyphenyl)porphyrin (ZnTCPP), the photosensitization of $\mathrm{TiO}_{2}$ electrodes by porply rins has been extensively studied. ${ }^{2}$

Inferior performances of porphyrins to ruthenium polypyriridyl complexes as photosensitizers would be attributed to the limited light absorption. poor matching to solar light distribution. A strategy to solve this problem is to make a strong and narrow Soret band broad and weak $Q$ bands strong by extension of the porphy rin $\pi$-system by modifying a $\beta$-position. ?

It is known that attachment of a thienyl unit induced a bathochromic shift. an intensification of the absorptivity and an increased lifetime of the excited-state. ${ }^{+}$Siebbeles found t-ethyl
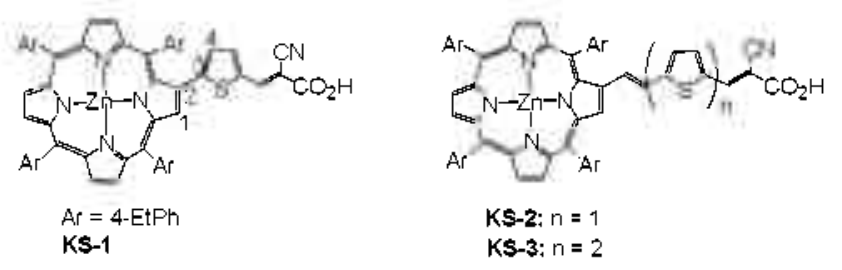

Figure 1. Chemical structure of dyes.

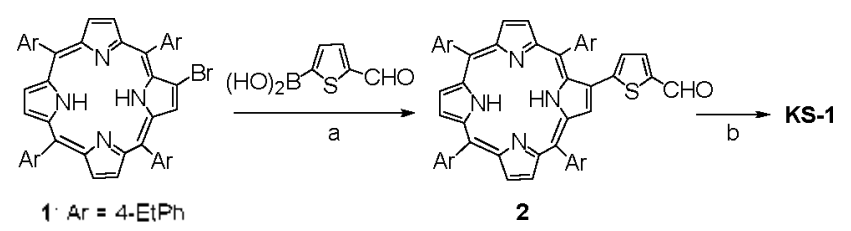

Scheme 1. (a) $\mathrm{Pd}\left(\mathrm{PPh}_{1}\right)_{4}, \mathrm{~K}_{2} \mathrm{CO}_{3} /$ toluene, reflux, 2 days (25\%) (b) (i) $\mathrm{Zn}(\mathrm{OAc}) / \mathrm{CH}_{2} \mathrm{Cl}_{2}-\mathrm{MeOH}, \mathrm{rt}, 5 \mathrm{~h}$; (ii) cyanoacetic acid piperidine/ $\mathrm{CH}_{3} \mathrm{CN}$, reflux, ovemight $(56 \%)$

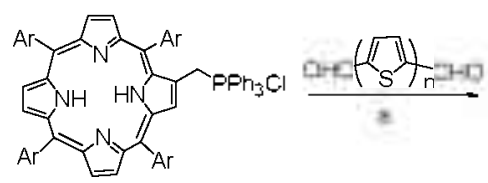

$3 \cdot \mathrm{Ar}_{\mathrm{r}}=4 \cdot \mathrm{Et} \cdot \mathrm{Ph}$

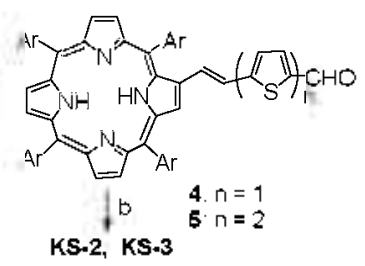

Scheme 2. (a) (i) DBU/ $\mathrm{CH}_{2} \mathrm{Cl}_{2}$, rt, $30 \mathrm{mim}$; (ii) $\mathrm{I}_{2}, 1 \mathrm{t}$, overnight $(69 \%$ for 4, $81 \%$ for 5 ) (b) (i) $\mathrm{Zn}(\mathrm{OAc}) / \mathrm{CH}_{2} \mathrm{Cl}_{2}-\mathrm{MeOH}$, it, $5 \mathrm{~h}$ : (ii) cyanoacetic acid, piperidine $/ \mathrm{CH}_{3} \mathrm{CN}$, reflux, overnight $(81 \%$ for $\mathrm{KS}-2,76 \%$ for $\mathrm{KS}-3$ ) group of meso-phenyl exhibit a maximum charge separation efficiency over other porphyrin derivatives. ${ }^{5}$

At this moment. to explore nature of the linker between porphyrin and anchoring group. $\beta$-substituted porphyrins KS-1. $\mathrm{KS}-2$ and KS-3 containing thiophene linker and etlyy group on meso-phenyl group were synthesized and characterized their photoelectronic properties.

Synthesis of KS-1, KS-2 and KS-3 were readily achieved from key intermediates $\mathbf{1}^{3}$ and $\mathbf{4}^{\mathrm{s}}$ using Suzuki coupling reaction and Wittig reaction (Scheme 1 and 2 ).

The UV-Vis spectra of KS-1. KS-2 and KS-3 show a series of bands between 400 and $650 \mathrm{~nm}$ due to $\pi$ - $\pi^{*}$ transitions on the conjugated nacrocycle that are red-shifted with respect to the B- and Q-bands of ZnTCPP.

Absorption intensity of KS-2 and KS-3 at $450-550$ 1un were drastically increased compared to ZnTCPP as we expected. However a narrower absorption spectrum of KS-1 means inefficient conjugation between porphyrin and thiophene ring. In energy minimized structure of KS- $1 .{ }^{8}$ the thiophene ring plane is largely deviated from porphyrin ring plane (dihedral angle of $\mathrm{Cl}-\mathrm{C} 2-\mathrm{C} 3-\mathrm{C}+$ in Fig. 1: 49 degree) due to the steric hinderence between meso-aryl and thiophene. ${ }^{8}$

DSSC based on synthesized dyes were fabricated according to reference. ${ }^{9}$ Quantity of anchoring dye and cell efficiency depend on dye dipping time $\left(2 \times 10^{-4} \mathrm{M}\right.$ in EtOH $)$ in the absence of co-adsorbate. The longer dipping time increased the cell efficiency of KS-1 ( $2 \mathrm{ht}: \eta=0.9 \% .24 \mathrm{~h}: \eta=1.5 \%$ ) but decreased those of KS-2 $(2 \mathrm{~h}: \eta=2.2 \% .24 \mathrm{~h}: \eta=1.4 \%)$ and KS-3 $(2 \mathrm{~h}$ : $\eta=2.5 \% .2+\mathrm{h}: \eta=1.8 \%$ ) even though the quantity of anchored dye were increased in all cases. These results show that KS-2

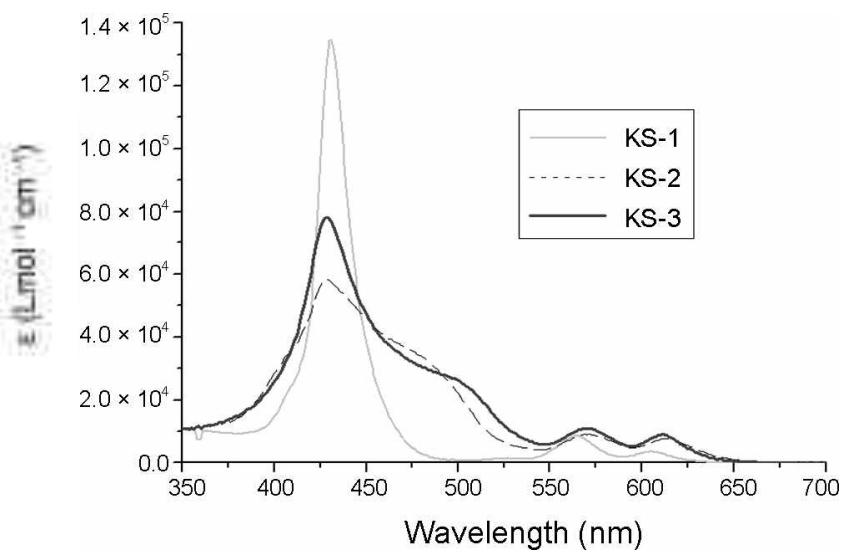

Figure 2. UV-Vis spectra of dyes in THF solution. 

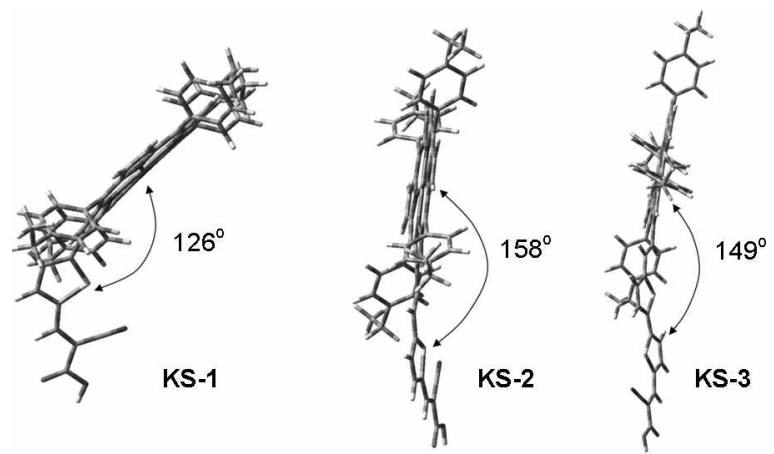

Figure 3. Optmized structures of dyes.

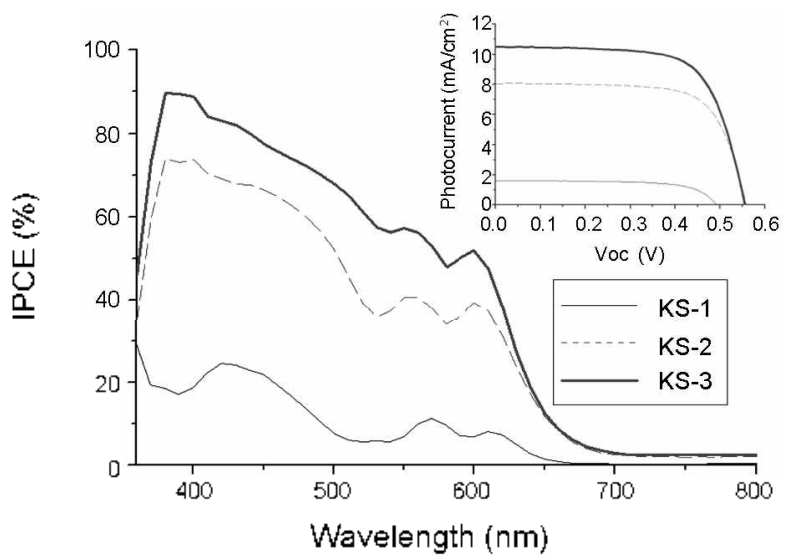

Figure 4. IPCE spectra for DSSC based on dyes under AM 1.5 inadiation.

and KS-3 have a tendency to undergo aggregation due to its almost planar structure (Fig. 3) which resulted to the reduced cell efficiency. However. the bent structure of $\mathrm{KS}-1$ was able to suppress the aggregation (Fig. 3).

The aggregation problem of $\mathrm{KS}-2$ and $\mathrm{KS}-3$ was resolved by using chenodeoxycholic acid (CDCA) as a co-adsorbate $(0.2$ $m \mathrm{M}$ dye and $10 \mathrm{mM}$ CDCA in THF, dipping time: $2+$ h) which resulted to more than twice of the analogues without CDCA. (Table 1) Even though KS-2 and KS-3 show similar UV-Vis absorption spectrum and same fashion of IPCE (Fig. 4). $J_{5 \mathrm{SC}}$ of $\mathrm{KS}-3$ is higher than that of KS-2. Main difference of KS-2 from $\mathrm{KS}-3$ is length of linker and quantity of anchored dye on $\mathrm{TiO}_{2}$. (quantity of anchored dye on $\mathrm{TiO}_{2}$ after $2+\mathrm{h}$ dipping: $\mathrm{KS}-1$ : $2.5 \times 10^{-8} \mathrm{~mol} \mathrm{~cm}-\mathrm{KS}-2: 4.1 \times 10^{-8} \mathrm{~mol} \mathrm{~cm}{ }^{-2} . \mathrm{KS}-3: 4.6 \times 10^{-8}$

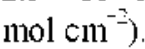

The low binding ability of KS-I can be explained due to the shorter length of linker and bent structure (Fig. 4). ${ }^{8}$ Porphy rin ring plane of KS-I is largely bent from the linker group. leading to steric hinderance between porphy rin moiety and surface of $\mathrm{TiO}_{2}$.

The elimination of the $\mathrm{C}=\mathrm{C}$ double bond of $\mathrm{KS}-2$ giving $\mathrm{KS}-\mathrm{I}$ was done to prevent the possible photoisomerization which could
Table 1. Photovoltaic performances of DSSC using KS-1, KS-2 , and KS-3

\begin{tabular}{ccccc}
\hline Dyes & $J_{\mathrm{s}}\left(\mathrm{mA} \mathrm{cm}^{-2}\right)$ & $\Gamma_{\mathrm{N}}(\mathrm{V})$ & $\mathrm{ff}$ & $\eta^{\sigma}(\%)$ \\
\hline $\mathrm{KS}-1$ & 1.6 & 0.49 & 67.5 & 0.5 \\
$\mathrm{KS}-2$ & 11.8 & 0.60 & 63.9 & 3.2 \\
$\mathrm{KS}-3$ & 13.0 & 0.61 & 65.9 & 4.0 \\
\hline
\end{tabular}

${ }^{a}$ Performances of DSSCs were measured with $0.16 \mathrm{~cm}^{2}$ working area. Electrolyte: $0.6 \mathrm{M}$ DMPImI, $0.05 \mathrm{M} \mathrm{I}_{2}, 0.1 \mathrm{M}$ Lil. $0.5 \mathrm{M}$ TBP in acetonitrile.

decrease efficiency. ${ }^{11}$ However contrary to our expectation the efficiency of KS- 1 is much lower than KS-2. Low efficiency of $\mathrm{KS}-\mathrm{I}$ can be explained partly due to very narrow and blue shifted absorption spectrum. Furthermore, it is noteworthy that the quantity of anchored dye KS- 1 on $\mathrm{TiO}_{2}$ is lower than those of KS-2 and KS-3. Efficiency of KS- 1 was drastically decreased after one week while those of KS-2 and KS-3 were retained. This result shows that low binding ability of $\mathrm{KS}-\mathrm{l}$ caused dye desorption from $\mathrm{TiO}_{2}$ surface into electrolyte.

In conclusion conformation of dye can affect not only on binding ability to $\mathrm{TiO}_{2}$ but also dỵe aggregation and conjugation. Low efficiency of KS-1 can be explained by narrow absorption spectrum and low binding ability. The low binding ability of KS- 1 caused serious dye desorption after cell fabrication. A maximum $\eta$ value of $4.0 \%$ is achieved under AM 1.5 irradiation with a DSSC based on KS-3. To obtain a better $/$, further optimization of molecular design based on KS-3 and the fabricated fundamental conditions of DSSCs will be studied in detail in our future work.

Acknowledgments. This paper was supported by research funds of Kunsan National University.

\section{References}

1. Liu, Z. M.; Yasseri, A. A.; Lindsey, J. S.; Bocian, D. F. Science $2003,302,1543$

2. Vlachopoulos, N.: Liska, P.: Mcevoy, A. J.: Gratzel, M. Surf. Sci. $1987,189,823$

3. Wang. Q.; Camphell, W. M.; Bontantani, E. E.; Jolley, K. W: Otťicer, D. L.; Walsh, P. T.; Gordon, K; Humpluy-Baker, R:; Nazeeruddin, Md. K: Gratzel, M. J. Pths. Chem. B 2005, 109 , 15397.

4. Zlessel, R.: Banerle, P.: Ammann, M.: Barbien, A.: Bangellettı, F. Chem. Commun. 2005, 802.

5. Huijser, A.; Savenije, T. J.; Siebbeles, L. D. A. Thin Solid Filmms 2006, 511-512,208

6. Zhou, X.: Tse, M. K.: Wan, T. S. M.: Chan, K. S. J. Ong. Chem. $1996,61,3590$

7. Nappa, M; Valentine, J. S. J. Am. Chem. Soc. 1978, 100, 5075.

8. Optimized structures were obtained at BiLYP/6-3G (d) using G03.

9. Chol, H.: Baik, C.: Kang, S. O.: Ko, J:- Kang, M.-S.: Nazeerndddm, M. K.: Grătzel, M. Angew. Chem. Int. Ed. 2009, $\$ 8,1712$.

10. Chen, R.; Yang, X.; Tran, H.; Sun, L. J. Photochem and Photobiologi A: Chem 2007, 189, 295. 